\title{
Hair, sweat and tears
}

\author{
Sarah Abdo, Katherine Samaras \\ Endocrinology Department, St Vincents hospital, Sydney, Australia
}

Correspondence to Dr Sarah Abdo, drsarahabdo@gmail.com

\section{Summary}

Hirsutism is a frequent and distressing presenting symptom in women, often in the setting of menstrual irregularity and acne. While polycystic ovarian syndrome is a common cause, the differential diagnosis of hirsutism is wide ranging and requires a thorough history and appropriate investigations to exclude potentially serious underlying causes. Several serious underlying conditions require active exclusion, otherwise patients are at risk of missed diagnosis and long-term sequelae of the untreated primary disease. The authors present a case of acromegaly where longstanding hirsutism was the presenting symptom.

\section{BACKGROUND}

Hirsutism is a common problem. It is often considered cosmetic and, by virtue of this, its significance with regard to potentially serious underlying disease is often diminished. Each of the two cases presented had underlying acromegaly with considerable medical and mental health sequelae. By highlighting the unique suffering and, in the case of the younger woman, guarded outcomes of what presented as a superficial problem, we hope clinicians will actively consider and exclude serious diseases in hirsute women.

Acromegaly is a rare condition ${ }^{1}$ and may be characterised by hyperandrogenism, hirsutism, acanthosis nigricans and polycystic ovary syndrome (PCOS). The sequelae of acromegaly include disabling and disfiguring skeletal changes and metabolic diseases such as diabetes mellitus and its complications. Recognition can be difficult since clinical features are often subtle early in the disease. Acromegaly is associated with a 3 -fold increase in mortality, primarily from cancer and cardiovascular disease. ${ }^{2}$ The long-term sequelae of missed diagnosis are highlighted in the case presented and provide a justification for active exclusion of acromegaly. History taking and physical examination provided the prompt for active biochemical investigation for acromegaly.

\section{CASE PRESENTATION}

A 25-year-old woman presented to the ambulatory endocrinology clinic of our hospital for a second opinion on the management hirsutism, having received a prior diagnosis of PCOS and apparent 'insulin resistance'.

Initial endocrine evaluation had been made 6 months prior for hirsutism, acne, weight gain and deepening voice.
The hirsutism was severe, affecting face, chest, back and required weekly waxing and daily facial plucking (20-30 hairs). Initial investigations found low luteinizing hormone ( $\mathrm{LH})$, follicle-stimulating hormone (FSH) and oestradiol, a mildly elevated prolactin and normal dehydroepiandrosterone sulfate. A pelvic ultrasound was reported to be normal and it was concluded that although all the investigations were against a diagnosis of PCOS, this was still the most likely cause of hyperandrogenism in this young woman. Further investigations included $24 \mathrm{~h}$ urinary free cortisol, free androgen index, fasting plasma glucose, insulin and an oral glucose tolerance test. A diagnosis of PCOS was made based on an elevated free androgen index and elevated plasma fasting insulin, though these are not criteria in accepted guidelines. A trial of a contraceptive pill containing ethinyl oestradiol $35 \mathrm{mg}$ and cyproterone acetate $2 \mathrm{mg}$ was initiated. The patient ceased this after 1 month due to depressed mood and constant tearfulness without any improvement in her presenting symptoms.

At presentation to our clinic, her symptoms dated back at least 3 years and included weight gain of $15 \mathrm{~kg}$. Important historical details actively sought, revealed constant sweating, deepening voice, hand swelling, stiffness and paraesthesiae in her hands and feet, an increase in foot size by three shoe sizes, coarsening facial features, development of facial hair and snoring (figure 1). Her menstrual cycle had been regular with intermittent menorrhagia and dysmenorrhea.

The vital signs were normal. Classic acromegalic features were evident: facial broadening, prominent brow, jaw protrusion, but no macroglossia. There was facial acne, hirsutism, multiple skin tags and acanthosis nigricans in skin
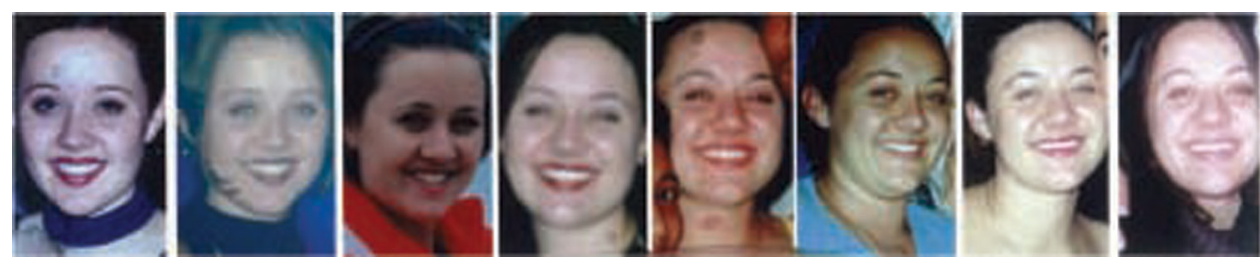

Figure 1 Changing appearance over 8 years from age 17 on the left through to age 25 on the right. 
folds and at the neck. The hands and fingers were swollen. The remainder of the physical examination including visual fields was normal.

\section{INVESTIGATIONS}

Investigations in our young woman found an elevated random growth hormone $(\mathrm{GH})$ of $317 \mathrm{mU} / 1(0-10)$ and an elevated insulin-like growth factor 1 (IGF-1) at 5.42 $\mathrm{U} / \mathrm{ml}(0.4-1.6)$. Prolactin was mildly raised at $630 \mathrm{mIU} / \mathrm{l}$ (50-370). Cortisol and thyroid hormone levels were normal. An MRI of the pituitary revealed a macroadenoma of the pituitary invading upwards into the left cavernous sinus, almost abutting the optic chiasm and encasing the left internal carotid artery.

\section{TREATMENT}

The young woman proceeded to transphenoidal hypophysectomy for tumour debulking. Due to the extensive disease extending into the cavernous sinus and encasing the carotid artery, complete tumour debulking was not possible. The postoperative GH and IGF-1 levels were persistently elevated. There was postoperative hypopituitarism requiring thyroxine, corticosteroid, vasopressin and gonadal replacement. Adrenocorticotropic hormone deficiency was confirmed by insulin-induced hypoglycaemia testing. The patient was commenced on long acting octreotide $30 \mathrm{mg}$ IMI monthly, cabergoline $0.5 \mathrm{mg}$ weekly and ethinyl estradiol $50 \mathrm{mg}$ (in a cyclical OCP) as a threepronged approach for suppression of $\mathrm{GH}$ and circulating IGF-1 levels. Pituitary replacement therapy consisted of prednisone $2.5 \mathrm{mg}$ daily, thyroxine $100 \mathrm{mg}$ daily and desmopressin $0.5 \mathrm{mg}$ twice daily.

\section{OUTCOME AND FOLLOW-UP}

There was a significant reduction in the degree of hirsutism, which required monthly (rather than weekly) depilation. Facial plucking daily was still required but reduced, as was the intensity of sweating.

Residual tumour mass on imaging, ongoing symptoms and persistently elevated growth hormone and IGF-1 levels indicated ongoing, active acromegaly 6 months postsurgery and stereotactic radiotherapy was undertaken. This mode of radiotherapy was chosen over external beam therapy due to the young age of the patient and the long-term risk of post radiotherapy sequlae. Although it is important to note that large macroadenomas that abut the optic chiasm may be more suited to external beam radiotherapy.

Over the following year her symptoms of acromegaly improved, including reduction in facial hair, sweatiness and reduced peripheral oedema. Most recently, there is evidence for active acromegaly (GH $12.6 \mathrm{mU} / \mathrm{l}(0-10)$, IGF-1 $63 \mathrm{nmol} / \mathrm{l}(14-40))$ despite medical therapy and symptoms of sweating recur if monthly octreotide injections are delayed.

Further neurosurgery has been considered, however the location of the residual tumour around the internal carotid artery mandates caution. Jaw and facial reconstruction are planned due to dental malocclusion and jaw pain. Ongoing clinical issues are chronic active acromegaly in this young woman, physical disfigurement and possible future comorbidities related to ongoing active disease.

\section{DISCUSSION}

Acromegaly is rare, with an annual incidence of 3 to 4 cases per million people. The age at diagnosis is generally 40 to 50 years. Approximately $75 \%$ of cases are caused by pituitary macroadenomas ( $>10 \mathrm{~mm}$ in diameter). ${ }^{2}$ PCOS on the other hand is a very commonly diagnosed disorder, with estimated premenopausal prevalence of $5-10 \%$. Criteria proposed to establish a diagnosis of the PCOS include oligoovulation or anovulation, biochemical evidence or clinical evidence of hyperandrogenism (e.g., hirsutism, acne, or male-pattern alopecia), polycystic ovaries on ultrasonography, and the absence of other causes. Consensus groups continue to debate the specific criteria. Disorders that can mimic the PCOS phenotype include non-classic congenital adrenal hyperplasia, hyperprolactinemia, Cushing's syndrome, acromegaly, androgen-secreting tumours of the adrenal glands or ovary, genetic syndromes of severe insulin resistance and some medications. ${ }^{3}$

Our case presented with signs of hyperandrogenism only. Against the diagnosis of PCOS were low LH, FSH and oestradiol. While some causes of hyperandrogenism were initially excluded, acromegaly was not. Historical interrogation pointed to the diagnosis of acromegaly, particularly the prominent symptom of sweating. The examination of fasting insulin to diagnose insulin resistance perhaps misled clinical attention away from the underlying problem. It is well understood that there is no clinically valid and reliable test for measuring insulin resistance, which are more appropriately used in research settings. ${ }^{4}$

This case, as well as others we have seen in our clinic highlights the need to consider underlying causes of the polycystic ovary syndrome phenotype in youth and in advanced age. In many cases, historical and clinical features were suggestive of acromegaly; measurement of $\mathrm{GH}$ and IGF-1 levels could ideally have been performed earlier.

The prevalence of menstrual irregularity in acromegalic females is high. In a study of 14 women with active acromegaly, $50 \%$ had polycystic ovaries on ultrasonography and $43 \%$ fulfilled the Rotterdam criteria for the phenotype of the polycystic ovary syndrome. ${ }^{5}$ Women with acromegaly frequently have signs and symptoms of hyperandrogenism, with normal estrogen and testosterone levels and low sex hormone-binding globulin levels. Acromegaly contributes to the development of PCOS either directly through $\mathrm{GH}$ and IGF-1 mediated effects or indirectly through hyperinsulinemia and ovarian-adrenal androgen synthesis. ${ }^{6}$ In the case reported by Hashimoto et al, the reduction of $\mathrm{GH}$ excess by surgery or medical therapy reversed these changes and decreased androgen production. ${ }^{7}$

In this case, a young woman with hirsutism for several years was incorrectly diagnosed with PCOS. A delayed diagnosis of acromegaly occurred after self-initiating a second endocrine opinion. It is tempting to consider whether her outcomes may have been improved by earlier diagnosis and intervention. Without considering and, where relevant, excluding acromegaly, it is indeed a very rare disease. 


\section{BMJ Case Reports}

\section{Learning points}

- Hirsutism is a common presentation and PCOS a common disease. With both, serious endocrine causes require active exclusion by careful history taking, physical examination and where appropriate, laboratory investigation.

- In a hirsute woman, key historical questions that may point to underlying acromegaly include a history of sweating, swelling of the fingers or feet, changes in ring or shoe size, headaches, jaw malocclusion and snoring. Clinical features should be carefully sought and excluded. Initial biochemical investigations include a random $\mathrm{GH}$ and IGF-1 level, interpreted using ageappropriate ranges. Expert endocrine opinion can be sought if abnormalities are suspected or found.

- It is important for physicians to remember that a diagnosis of polycystic ovaries is the beginning and not the end of the investigation, and one needs to consider secondary causes such as congenital adrenal hyperplasia, Cushing's syndrome, virilising tumours and indeed acromegaly.
Competing interests None.

Patient consent Obtained.

\section{REFERENCES}

1. Unal A, Sahin Y, Kele timur F. Acromegaly with polycystic ovaries, hyperandrogenism, hirsutism, insulin resistance and acanthosis nigricans: a case report. Endocr J 1993;40:207-11.

2. Molitch ME. Clinical manifestations of acromegaly. Endocrinol Metab Clin North Am 1992;21:597-614.

3. Utz AL, Schaefer PW, Snuderl M. Case records of the Massachusetts General Hospital. Case 20-2010. A 32-year-old woman with oligomenorrhea and infertility. N Engl J Med 2010;363:178-86.

4. Samaras K, McElduff A, Twigg SM, et al. Insulin levels in insulin resistance: phantom of the metabolic opera? Med J Aust 2006;185:159-61.

5. Kaltsas GA, Androulakis II, Tziveriotis K, et al. Polycystic ovaries and the polycystic ovary syndrome phenotype in women with active acromegaly. Clin Endocrinol (Oxf) 2007;67:917-22.

6. Goto J, Otsuka F, Inagaki K, et al. Effects of growth hormone reduction in a patient with polycystic ovary syndrome complicated with acromegaly. Endocr J 2009:56:157-60.

7. Hashimoto S, Yatabe J, Midorikawa S, et al. Inhibition of growth hormone excess reduces insulin resistance and ovarian dysfunction in a lean case of polycystic ovary syndrome with a growth-hormone-producing pituitary adenoma. Horm Res 2003;59:149-55.

This pdf has been created automatically from the final edited text and images.

Copyright 2011 BMJ Publishing Group. All rights reserved. For permission to reuse any of this content visit

http://group.bmj.com/group/rights-licensing/permissions.

BMJ Case Report Fellows may re-use this article for personal use and teaching without any further permission.

Please cite this article as follows (you will need to access the article online to obtain the date of publication).

Abdo S, Samaras K. Hair, sweat and tears. BMJ Case Reports 2011;10.1136/bcr.05.2011.4177, date of publication

Become a Fellow of BMJ Case Reports today and you can:

- Submit as many cases as you like

- Enjoy fast sympathetic peer review and rapid publication of accepted articles

- Access all the published articles

- Re-use any of the published material for personal use and teaching without further permission

For information on Institutional Fellowships contact consortiasales@bmjgroup.com

Visit casereports.bmj.com for more articles like this and to become a Fellow 